\title{
Characterization of sugarcane bagasse ash (SBA) and its evaluation for use in alkali-activated slag mixtures
}

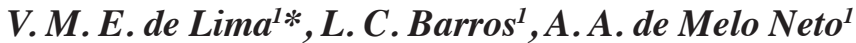 \\ ${ }^{I}$ Federal University of Pernambuco, LabTag, Av. da Arquitetura, s $n$, Recife, PE, Brazil
}

\begin{abstract}
This work proposed to incorporate the sugarcane bagasse ash (SBA) with a high content of organic matter (loss on ignition of $35.87 \%$ ) in alkali-activated mixtures with blast furnace slag. After grinding SBA, replacement ratios of 10\%, 20\%, and 30\% of the ground ash were used for the flowability evaluation. The mixtures containing $20 \%$ and $30 \%$ showed a dry consistency, then only the mixture with $10 \%$ of slag was used for the other tests. The use of an air-entraining admixture led to an improvement in the flowability of the alkali-activated mixtures. X-ray diffraction results showed that both SBA and the air-entraining admixture did not interfere in the mineralogical composition of the hydrated products. However, the use of SBA led to a decrease in the compressive strength of about $20 \%$ to $28 \%$. In conclusion, SBA proved to be viable for use in alkali-activated mixtures considering its effect on mechanical performance.
\end{abstract}

Keywords: sugarcane bagasse ash, blast furnace slag, alkaline activation.

\section{INTRODUCTION}

Due to the growing concern of society with environmental issues, the adoption of low environmental impact technology solutions is a worldwide trend. Within this context is the construction industry, which has a remarkable consumption of natural and manufactured resources. Cement, the most consumed product in this industry, was responsible for the emission of $7 \%$ of the $\mathrm{CO}_{2}$ generated worldwide in 2017 [1]. One of the solutions adopted for the reduction of $\mathrm{CO}_{2}$ generation is the use of supplementary cementitious materials, which include mineral admixtures as metakaolin, fly ash, silica fume, limestone filler, and blast furnace slag. These materials are characterized by their low environmental impact and increasing usage in civil construction [2]. They can be used either as a partial replacement for Portland cement or as a full replacement when employed as alkaliactivated binders (AABs) [3, 4]. AABs are characterized as materials that have dissolution capacity and subsequently produce resistant products only when activated by an alkaline solution. Generally, the alkaline activators are solutions composed of sodium hydroxide and sodium silicate. Depending on the intrinsic alkalinity of the material and its amorphous material content, the dosage of the alkaline solution is studied to obtain compressive strength values compatible with those generally obtained in Portland cement products. As a rule, the higher the alkalinity of the material, the less alkaline the solution required for its activation. The alkalinity of materials can be measured by several equations, such as Eq. A [5], where the material is considered alkaline when $\mathrm{A}>1$. Regarding crystallinity, the higher the amorphous content, the greater the potential of this material for activation.

$$
\mathrm{A}=\frac{\mathrm{CaO}(\%)+\mathrm{MgO}(\%)}{\mathrm{SiO}_{2}(\%)}
$$

Taking into account the factors explained above, it can be said that calcium-rich materials, such as blast furnace slag (BFS), have greater potential for use as AAB, and their use for this purpose has been occurring since the 1960s in the extinct Soviet Union [6]. However, the main problems that make the use of large-scale activated slag unfeasible are its rapid loss of flowability and its intense autogenous and drying shrinkage. Not yet exist in the literature [7,8] an admixture that can be used in sodium silicate activated BFS, such as solutions that succeed in delaying setting time or shrinking without reducing the mechanical performance of the hardened mixture. Regarding shrinkage, partial replacement of BFS by less reactive alkaline materials, such as pozzolans, may help mitigate this problem, but may also be responsible for decreasing the mechanical performance $[9,10]$. The most common pozzolans for alkaline activation are metakaolin and fly ash, which are often used either as a partial replacement for BFS or as binary mixtures with each other [11-18]. The main product resulting from the chemical activation of BFS is the C-(A)-S-H gel, whereas in calcium-poor materials $\mathrm{K}, \mathrm{N}-(\mathrm{A})-\mathrm{S}-\mathrm{H}$ gel and zeolites with similar chemical compositions are formed. C-(A)-S-H has a structure similar to that of reasonably polymerized $14 \AA$ tobermorite, while $\mathrm{K}, \mathrm{N}-(\mathrm{A})-\mathrm{S}-\mathrm{H}$ has a more polymerized and cross-linked structure forming macromolecules [19]. Because of this feature, $\mathrm{K}, \mathrm{N}-(\mathrm{A})-\mathrm{S}-\mathrm{H}$ gel-forming AABs are often referred to in the literature as 'geopolymers'.

One group of materials with potential for use as supplementary cementitious material is composed of the ashes from vegetable waste. These include the ashes of rice husk, wheat, sugarcane bagasse, and sugarcane straw [20]. These materials are characterized by the presence of at least $50 \%$ of silica in their chemical composition and 
may reach $90 \%$ as in the case of rice husk ash. Part of this silica, however, may be crystalline or amorphous, depending on the conditions under which these materials are burned. Sugarcane bagasse ash (SBA) is obtained by burning the bagasse in a power plant boiler, where the temperature can vary between 300 and $900{ }^{\circ} \mathrm{C}$ [21-23]. Due to the lack of control of the burning temperature, SBA may come out of the boiler with an organic matter content ranging from $17 \%$ to $32 \%$ [24-28], decreasing its potential for use as pozzolan or alkaline activation. Controlled processes such as calcination and grinding can improve SBA performance, however, require a reasonable cost for large scale application. The recycling of SBA and its use in ceramic materials are widely discussed in the literature [23, 26, 27, 29-36]. This waste has a limited capacity to be reutilized in the sugarcane production cycle, due to its low alkalinity (to correct the soil $\mathrm{pH}$ ) [37]. Therefore, it is important to study sustainable ways to dispose of this material and how to aggregate value to this waste. In this context, it is proposed to evaluate the incorporation of sugarcane bagasse ash in alkali-activated mixes to aggregate value to this waste. Research on alkaline activation, in general, used ash with low organic matter content [38-40]. This research, however, aimed to use ash with a high organic matter content and grinding as the only processing employed.

\section{EXPERIMENTAL}

At first, the physical, chemical, and mineralogical characterization of the materials was carried out. Then, flowability tests were performed in two steps. First, the minislump tests showed the feasibility to prepare pastes with $10 \%, 20 \%$, and $30 \%$ of SBA. After, the use of admixtures was tested in the mixtures. Lastly, tests on hardened pastes and mortars presented their hydrated products and mechanical performance.

Materials characterization: blast furnace slag (BFS) was provided by a steel mill located in the metropolitan region of Vitória-ES, Brazil, and the raw SBA (R-SBA) was collected at a sugar and alcohol plant in the Zona da Mata Norte region of Pernambuco, Brazil. Fig. 1 shows photos of the materials used. The R-SBA was ground using an alumina ball mill until the specific surface area (Blaine) of approximately $1000 \mathrm{~m}^{2} \cdot \mathrm{kg}^{-1}$ was reached. After processing, the ground SBA was named G-SBA. R-SBA was not employed in this work due to its high water absorption and coarse granulometry, which would make it impossible for the pastes to flow. The physical characterization of solid materials was performed by specific mass test (ABNT NBR 16605:2017 standard [41]), laser granulometry (Fig. 2), and Blaine fineness (ABNT NBR 16372:2015 standard [42]). The specific mass test was performed using a Le Chatelier flask. The particle size of the materials was analyzed by a laser granulometry test (Matersizer 2000, Malvern Instr.). The Blaine fineness was measured by an air permeability apparatus and along the laser granulometry test allowed a better comprehension of the particle size of the materials. Table I shows the main results obtained in the physical characterization. For the chemical and mineralogical characterizations, X-ray fluorescence spectroscopy (XRF, Table II), X-ray diffraction (XRD, Fig. 3), and thermogravimetric analysis (TGA) were employed. XRF was carried out with a spectrometer (RIX 3000 , Rigaku). For the XRD, it was utilized a diffractometer (D2 Phaser, Bruker) with $\mathrm{Cu}$ anode operated at $10 \mathrm{~mA}$ and

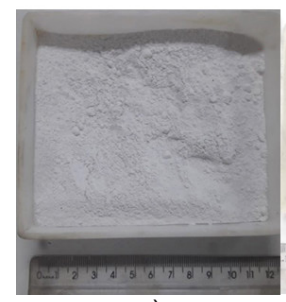

a)

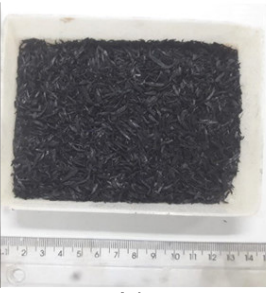

b)

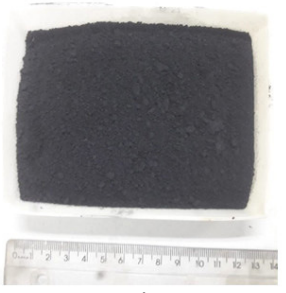

c)
Figure 1: Photos of: a) blast furnace slag (BFS); b) raw sugarcane bagasse ash (R-SBA); and c) ground SBA (G-SBA).

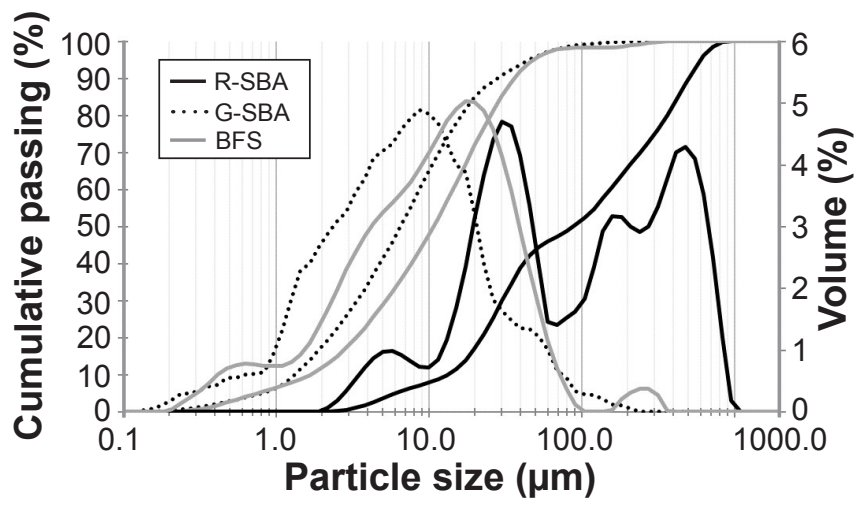

Figure 2: Cumulative and discrete particle size distribution curves of raw and ground SBA, and BFS.

Table I - Physical properties of the utilized materials.

\begin{tabular}{cccc}
\hline Property & R-SBA & G-SBA & BFS \\
\hline Blaine fineness $\left(\mathrm{m}^{2} / \mathrm{kg}\right)$ & 252 & 981 & 485 \\
Specific gravity $\left(\mathrm{g} / \mathrm{cm}^{3}\right)$ & 2.17 & 2.18 & 2.79 \\
$\mathrm{~d}_{50}(\mu \mathrm{m})$ & 99.91 & 7.49 & 12.33 \\
\hline
\end{tabular}

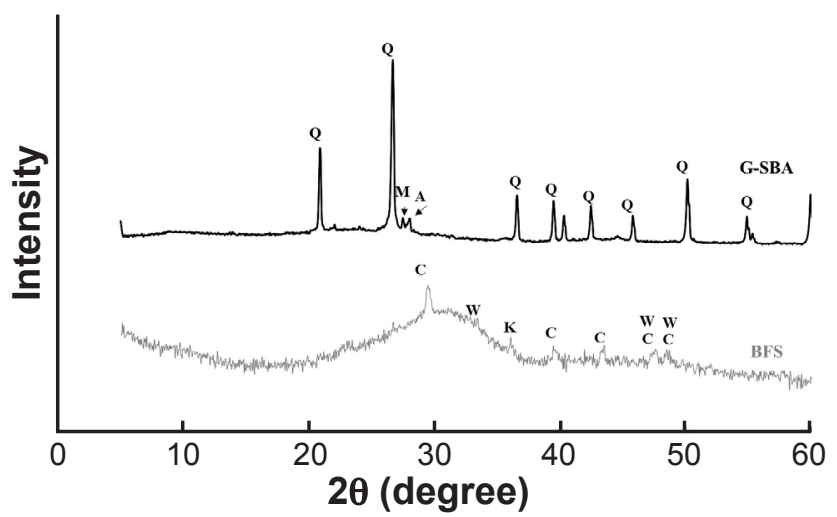

Figure 3: X-ray diffractograms of G-SBA and BFS showing peaks of quartz $(\mathrm{Q})$, microcline $(\mathrm{M})$, albite $(\mathrm{A})$, calcite $(\mathrm{C})$, merwinite $(\mathrm{W})$, and akermanite $(\mathrm{K})$. 
Table II - Chemical compositions (wt \%) of G-SBA and BFS.

\begin{tabular}{ccc}
\hline Oxide & G-SBA & BFS \\
\hline $\mathrm{SiO}_{2}$ & 56.42 & 37.73 \\
$\mathrm{Al}_{2} \mathrm{O}_{3}$ & 1.96 & 10.91 \\
$\mathrm{Fe}_{2} \mathrm{O}_{3}$ & 1.05 & 0.38 \\
$\mathrm{CaO}$ & 0.94 & 42.00 \\
$\mathrm{MgO}$ & 0.84 & 6.04 \\
$\mathrm{~K}_{2} \mathrm{O}$ & 1.62 & 0.46 \\
$\mathrm{Na}_{2} \mathrm{O}$ & 0.56 & 0.40 \\
$\mathrm{TiO}_{2}$ & 0.21 & 0.52 \\
$\mathrm{SO}_{3}$ & 0.07 & 0.33 \\
$\mathrm{LOI}$ & 35.87 & 1.24 \\
\hline
\end{tabular}

LOI - loss on ignition.

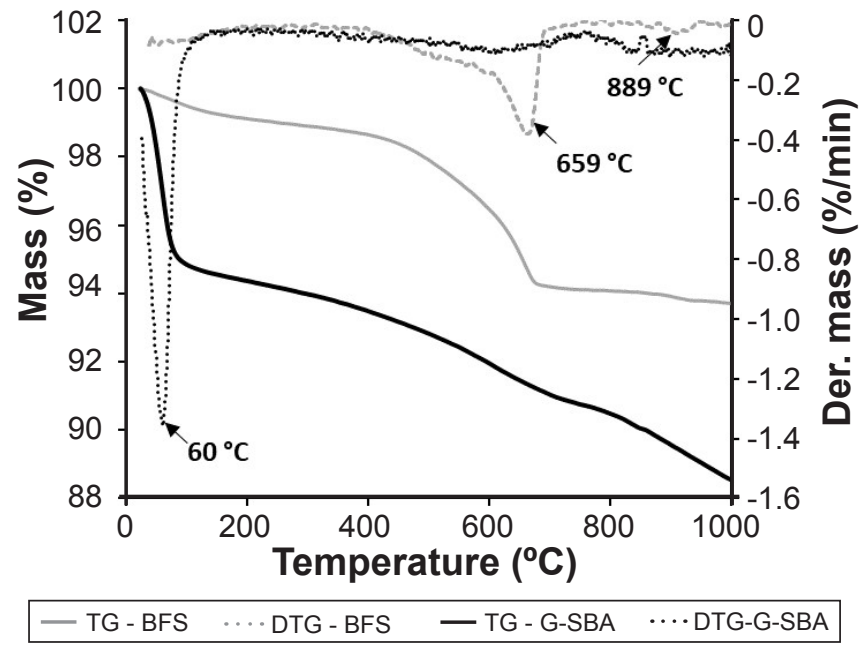

Figure 4: Curves of thermogravimetric analysis of BFS and SBA.

$30 \mathrm{kV}$. The parameters used in this test were: goniometer rotation at $10 \mathrm{rpm}$; speed scan of $5.1^{\circ} \cdot \mathrm{min}^{-1}$; and $0.5 \mathrm{~s}$ of time per step. TGA was performed with a thermal analyzer (STA 449F3, Netzsch) with a heating rate of $10{ }^{\circ} \mathrm{C} \cdot \mathrm{min}^{-1}$ (Fig. 4). This test provided information on materials that presented gas release due to calcination in the range between 30 and $1000{ }^{\circ} \mathrm{C}$.

Flowability test: primarily, the feasibility to replace $10 \%$, $20 \%$, and $30 \%$ (in volume) of BFS by SBA was studied. At this stage, the consistency of the mixtures was assessed visually. The tests showed that mixtures with $20 \%$ and $30 \%$ of SBA showed a dry consistency, like 'crumbs', therefore these contents were discarded for the next tests. The mixtures with $10 \%$ BFS showed a suitable consistency, however, the paste with the ratio water/binder $\mathrm{w} / \mathrm{b}=0.28(\mathrm{~S} 90 \mathrm{~A} 10-28) \mathrm{did}$ not flow from the beaker. Hence, the liquid admixtures were employed aiming to improve the consistency of the pastes, because even the paste with no slag (S100-28) presented a quick loss of flowability. Then, the flowability of the pastes was analyzed utilizing the mini-slump test. This is a quick and easy test to assay the consistency of fresh pastes and the influence of admixtures on the flowability [43]. It is commonly used as an alternative to the Marsh funnel test [44, 45], which uses a larger amount of material. The procedure adopted in this test was the same as suggested in [46]. In summary, the pastes were prepared in a beaker, and after the mixing was finished, the samples were cast in a mini-cone supported on a glass plate. After removing the mini-cone, the samples spread in a circular shape, and then the spreading diameter was measured. The final diameter was considered as the average of two perpendicular measurements.

The solution used for alkaline activation was a sodium silicate with silica modulus $\left(\mathrm{SiO}_{2} / \mathrm{Na}_{2} \mathrm{O}\right.$ ratio) of 1.7. The dosage used for silicate was '4NS' [47], which sets the percentages of alkaline activator $\mathrm{Na}_{2} \mathrm{O}$ and $\mathrm{SiO}_{2}$ at $4.5 \%$ and $7.65 \%$, respectively, relative to the total binder mass. Melo Neto [48] described this dosage as the one that results in the highest values of compressive strength aiming at the alkaline activation of the slag with sodium silicate. Besides, this silicate dosage has been also used by Araújo Júnior [49], which obtained concrete with a compressive strength greater than $100 \mathrm{MPa}$. The total binder considered in the dosage was the sum of BFS, CBC, and the solids of the sodium silicate solution. Two water/binder ratios were selected: 0.28 and 0.40 . The purpose of this choice was to obtain mortars with different classes of compressive strength.

Aiming to improve the flowability of the mixtures, two admixtures were tested: a polycarboxylate-based superplasticizer (SP) and a sulfated salt-based air-entraining (AE). The superplasticizers are widely employed in cementbased mortar and concrete; however, researchers have divergent conclusions about their effect in alkali-activated mixes [44, 50-52]. The AE admixture is employed mainly in cement-based mortars to increase the air-entrained content and improve the consistency of the mortars. Nevertheless, its effect is not well known in alkali-activated mixes. Due to the known quick loss of workability of alkali-activated mixtures, the hypothesis was that SP or AE could be used as a hydration retarder or as a flowability improver. In cement-based materials, the dosage of superplasticizer is generally at most $1 \%$ (the dosage of admixtures is presented as the percentage, in mass, of the total amount of binder). However, in preliminary tests, it was observed that this dosage had no effect in alkali-activated mixtures. Therefore, dosages from $2 \%$ were used. On the other hand, the airentraining admixture worked with dosages up to $1 \%$; then, this dosage was used. The admixture with a better influence on flowability was selected for the preparation of pastes and mortars for the later tests. In the end, the variables were: the water/binder ratio ( 0.28 and 0.40$)$, the type of admixture (SP and AE), the content of SBA (0 and 10\%), and the dosage of admixture. In this last variable, the contents of admixture were: $0.5 \%$ and $1.0 \%$ for $\mathrm{AE}$ and $2.0 \%$ for SP. In addition, a combination of $4.0 \% \mathrm{SP}$ and $0.5 \% \mathrm{AE}$ were tested to evaluate concomitantly the performance of these two admixtures and the overdosage of SP. The mixtures were named according to the contents of BFS (S) and G-SBA (A) in volume, water/binder ratio ( 28 for 0.28 and 40 for 0.40 ), and the type and content of the admixture. For 
example, the mixture S90A10-40AE1.0 corresponded to a paste with $90 \%$ slag and $10 \% \mathrm{SBA}$, a water/binder ratio of 0.40 , and $1.0 \% \mathrm{AE}$.

Hardened state tests: the variations in the paste and mortar mix design were the volume substitution content of BFS by G-SBA in 0 and $10 \%$ and the water/binder ratio of 0.28 and 0.40 . The incorporation of air in $1.0 \%$ had the greatest influence on the fluidity of the paste and, therefore, this variation was included in the experimental program. Finally, 8 pastes for X-ray diffraction (XRD), and 8 mortar mixtures for compressive strength and ultrasound tests were prepared. The nomenclature type used was the same as for the mini-cone tests. The hydration stoppage employed submersion of the samples in liquid nitrogen at the ages of 3 and 7 days of hydration. Subsequently, the samples were freeze-dried at $-59{ }^{\circ} \mathrm{C}$ and then stored in a desiccator. The grinding of the pastes was performed with a laboratory mill, and the samples passing through sieve $n^{\circ} 200$ were separated for the XRD test. The parameters of this test were the same as those used for material characterization. Lastly, mortars were prepared for the compressive strength and ultrasound tests with the ratios of $1: 1$ cement:sand for $w / b=0.28$ and $1: 2$ cement:sand for $w / b=0.40$. The compression test was performed on $\phi 5 \times 10 \mathrm{~cm}$ cylindrical specimens, as prescribed by ABNT NBR 7215:2019 standard [53], at the ages of 3 and 7 days. The testing machine used (AGX-V, Shimadzu) had a maximum load capacity of $300 \mathrm{kN}$.

\section{RESULTS AND DISCUSSION}

Physical, chemical, and mineralogical properties of BFS and $S B A$ : in general, the properties of BFS were similar to those found in the literature [5, 46, 54]. The BFS alkalinity (A), according to Eq. A [5], resulted in a value of 1.27 ; therefore, the BFS used in this research can be considered as basic. Regarding mineralogical composition, calcite $\left(\mathrm{CaCO}_{3}\right.$, PDF 03-089-1305), akermanite $\left[\mathrm{Ca}_{2} \mathrm{Mg}\left(\mathrm{Si}_{2} \mathrm{O}_{7}\right)\right.$, PDF 03-076-0841], and merwinite $\left[\mathrm{Ca}_{3} \mathrm{Mg}\left(\mathrm{SiO}_{4}\right)_{2}, \mathrm{PDF}\right.$ 03-035-0591] were present, in addition to the characteristic

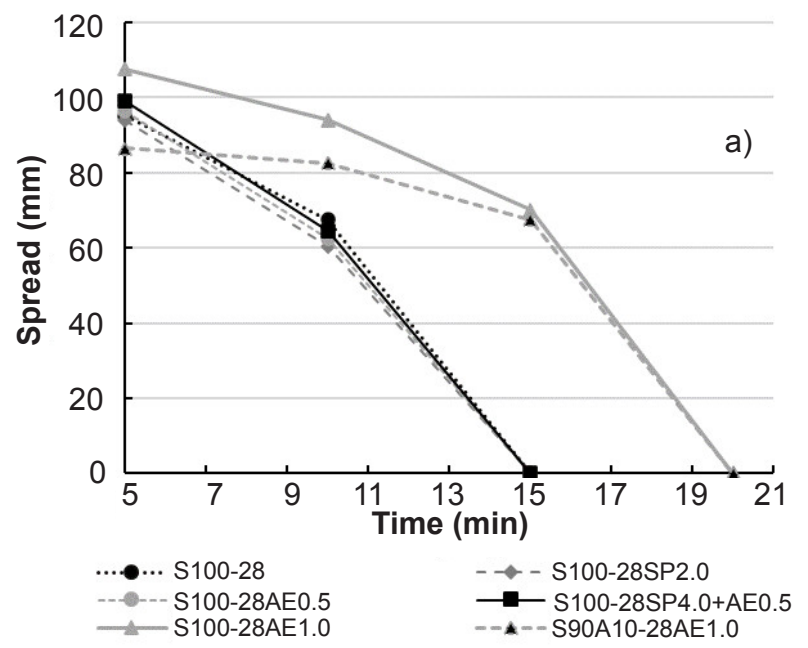

amorphous halo. Merwinite is considered a non-hydraulic mineral [55], however, its presence up to 5\% of the total slag composition is associated with a reactive slag with high compressive strength results [56,57]. Calcite is a product of slag carbonation, which mechanism is not yet well known, because unlike Portland cement-based products, calcium hydroxide (portlandite) hardly forms in the hydration reactions of activated slag. A problem with the appearance of calcite in XRD analysis in the pastes is due to the position of its peak, around $29.6^{\circ}(2 \theta)$, which generally coincides with the C-S-H peak. In the TGA curves (Fig. 4), peaks were observed at 659 and $889{ }^{\circ} \mathrm{C}$ due to the presence of carbonates [58].

Through the characterization of SBAs, there was a noticeable increase in the fineness of the ash after grinding. In addition to the change in the particle size distribution curves shown in Fig. 2, the average diameter $\left(\mathrm{d}_{50}\right)$ decreased from 99.91 to $7.49 \mu \mathrm{m}$ (Table I). The chemical composition (Table II) showed a loss on ignition of $35.87 \%$, a value above the range of results found in the literature [24-27]. This is an accurate indication of the incomplete burning of the SBA, which probably must have been burned in the boiler at a temperature in the lower level of the range of 300 to $900{ }^{\circ} \mathrm{C}$ mentioned above. The results of density presented no significant difference between raw and ground SBA. The mineralogical phases (Fig. 3) identified in G-SBA were: quartz $\left(\mathrm{SiO}_{2}\right.$, PDF 03-085-0794), microcline $\left(\mathrm{KAlSi}_{3} \mathrm{O}_{8}\right.$, PDF 03-019-0932), and albite [(Na,Ca) $\mathrm{Al}(\mathrm{Si}, \mathrm{Al})_{3} \mathrm{O}_{8}, \mathrm{PDF}$ 03-041-1480]. The presence of quartz probably occurred due to contamination of sugarcane bagasse during the crop [32]. For use in cementitious materials, quartz is undesirable because it reduces the content of materials with the ability to react and form resistant products, in addition to making grinding difficult, due to its high wear resistance [59]. Another problem with quartz is the high intensity of its peaks, which hinders the visualization of smaller peaks. The amorphous content measured by the software DIFFRAC. EVA 4.5 showed the amounts of $40.1 \%$ in G-SBA and $86.1 \%$ in BFS. TGA results (Fig. 4) showed an intense loss of mass

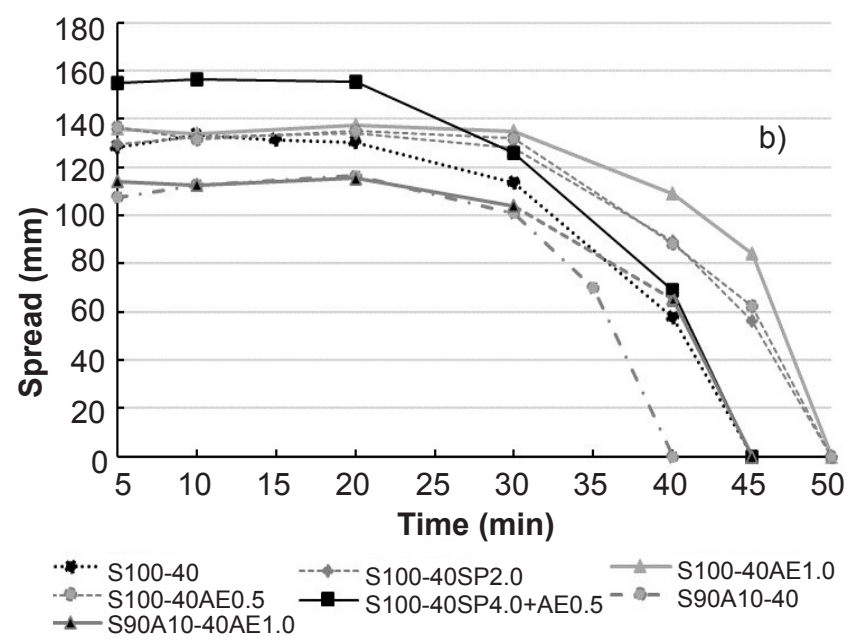

Figure 5: Results from mini-slump tests of pastes with water/binder ratio of: a) 0.28 ; and b) 0.40 . 
peaking at $60{ }^{\circ} \mathrm{C}$, due to the loss of water from organic matter. The calcination of the organic matter was clear due to the loss of mass almost constant from 100 to $1000{ }^{\circ} \mathrm{C}$. Small variations in loss or gain of mass during calcination also occur due to the oxidation and volatilization reactions of organic matter [40].

Fresh state - flowability test: in the mini-slump test, the first measurement was performed 5 min after the start of mixing, and the subsequent measurements were performed every 5 or 10 min. It was considered as 'zero' when the paste did not have enough fluidity to flow from the beaker. The results with the ratio water/binder $w / b=0.28$ (Fig. 5a) showed that the superplasticizer admixture had no effect on the mixture with superplasticizers, even using levels of $2.0 \%$ and $4.0 \%$, which would be considered excessive in Portland cement-based mixtures. This occurred due to the lack of chemical stability of polymeric compounds based on polycarboxylate in an alkaline medium [44, 52]. Air-entraining (AE) admixture showed similar behavior to the others when dosed at $0.5 \%$ of the binder mass; however, at $1.0 \%$, it caused a slight increase in the consistency of the paste. The incorporation of $10 \%$ of SBA (S90A10-28) resulted in a considerable decrease in the consistency of the pastes, making it impossible to perform the test with $\mathrm{w} / \mathrm{b}=0.28$ due to the high viscosity. However, when the air-entraining was added, there was an increase in fluidity, even though initially the spreading values were below the other mixtures in the first $5 \mathrm{~min}$. Considering the $\mathrm{w} / \mathrm{b}=0.40$ (Fig. 5b), a small increase in time was observed with $1.0 \%$ of AE. The use of $2.0 \%$ of superplasticizer also led to similar behavior. One hypothesis for this phenomenon may have been an increase in the $\mathrm{w} / \mathrm{b}$ ratio, which resulted in a decrease in the alkalinity of the solution. The addition of SBA without additive led to a decrease in open time because of its intense water absorption. As observed in the chemical composition, SBA had a high content of organic matter, which was responsible for retaining a high moisture content, a fact that was observed by the intense peak at $60^{\circ} \mathrm{C}$ in the TGA curve.

Hardened state tests. $X$-ray diffraction: XRD allowed to analyze the influence of the incorporation of $10 \%$ of SBA and the use of $\mathrm{AE}$ admixture in the formation of hydrated products in alkali-activated pastes. In addition to checking if there could be any changes in hydrated products, it was also analyzed whether there was any significant change in the delay in the production of these products. As seen in Fig. 6 , the mineralogical phases formed by the hydration of the activated slag pastes were calcite and calcium silicate hydrate $\left(\mathrm{Ca}_{1.5} \mathrm{SiO}_{3.5} \times \mathrm{xH}_{2} \mathrm{O}\right.$, PDF 03-033-0306). At 29.5 (20), an overlap of the C-S-H and calcite peaks was observed, which increased in intensity from 3 days (Fig. 6a) to 7 days (Fig. 6b). At 7 days, an appearance of a 'shoulder' around $28.3^{\circ}$ was also observed, which corresponded to the presence of C-A-S-H, indexed as a high-aluminum tobermorite $\left[\mathrm{Ca}_{5} \mathrm{Si}_{5} \mathrm{Al}(\mathrm{OH}) \mathrm{O}_{17} .5 \mathrm{H}_{2} \mathrm{O}\right.$, PDF 03-019-0052] [60, 61]. No change in the mineralogical composition was observed due to the $\mathrm{AE}$, as for the appearance of new hydrated products or for the delay in the production of C-S-H, which could be demonstrated by a decrease in the intensity of the peaks. The presence of quartz in the SBA resulted in the presence of this mineral in the diffractograms of the pastes. There was also no delay in the hydration chemical reactions.

Compressive strength: the results of compressive strength tests are presented in Table III. The highest values were from the reference mixtures (without SBA and $\mathrm{AE}$ ) and were 86.2 and $69.3 \mathrm{MPa}$ at 7 days for water/binder ratios of 0.28 and 0.40 , respectively. Compressive strength was a property notably affected by the incorporation of G-SBA and AE. The latter was responsible for a notable decrease in the compressive strength of the paste without G-SBA, due to the increase in internal porosity with the production of air bubbles. The high water absorption of G-SBA resulted in a decrease in the fluidity of the mortars, mainly in the ratio $\mathrm{w} / \mathrm{b}=0.28$ (S90A10-28), which harmed the compaction of the mortar in the mold and was responsible for the $27 \%$ decrease in strength at 7 days. With the addition of AE, however, the S90A10-28AE1.0 mixture showed a better cohesion. As a result, unexpectedly, its compressive strength increased from 50.1 to $59.8 \mathrm{MPa}$, in comparison to the analog mixture without AE (S90A10-28). Some theories can explain reasonably this phenomenon. The improvement in particle packing has been crucial to allow better compaction, and
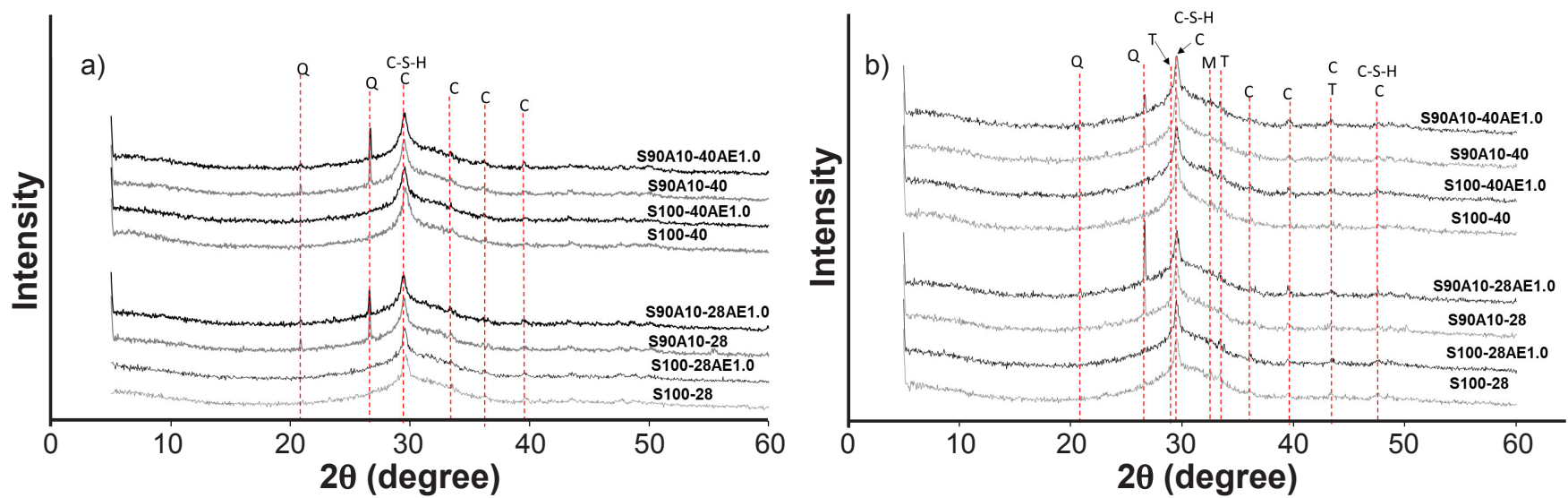

Figure 6: X-ray diffractograms of pastes after 3 days (a) and 7 days (b) of curing. Q: quartz; C-S-H: calcium silicate hydrate; C: calcite; T: aluminum tobermorite (C-A-S-H); M: merwinite. 
consequently, it reached a suitable consistency to expel the air bubbles. It is known that in dry mixtures, the compaction must employ greater energy to decrease the mixture porosity. Besides, the $\mathrm{AE}$ admixture is composed of approximately $50 \%$ of water, thus it increased the total amount of water in the mixture. Considering the ratio $\mathrm{w} / \mathrm{b}=0.40$, the effect of SBA on the compressive strength followed the same behavior. However, the addition of AE resulted in different behavior. In this case, the mixtures had a higher fluidity, and therefore G-SBA did not influence the compaction as much as in the other case. Regarding the $\mathrm{w} / \mathrm{b}=0.40$, the mixtures, even with G-SBA, presented a sufficient consistency to allow the AE admixture to form the air-bubbles, leading to an increase in the porosity and a decrease in the compressive strength. In general, the high fineness of ash (filler effect) did not compensate for its lack of reactivity and its high potential for water absorption. Regarding the resistance gain from 3 to 7 days, no significant influence was observed, since the percentage of compressive strength gain varied between $22 \%$ and $28 \%$. Researchers [38-40] showed that the incorporation of ash with low organic matter content $(\mathrm{LOI}<5 \%)$ can stabilize or even increase the compressive strength of mortar and concrete.

Ultrasound: the ultrasound test is often approached in the literature as a reasonable tool to estimate the compressive strength of concrete. However, the velocity of the ultrasonic pulse is closely linked to the porosity, which is not always directly linked to the compressive strength [62]. In this work, the velocity of the ultrasonic wave explained satisfactorily $\left(\mathrm{R}^{2}>0.8\right.$, Fig. 7) the results of compressive strength. The highest values of compressive strength corresponded exactly to the highest values of wave velocity. This occurred because when there is less porosity and, consequently, less air for the wave to travel, the velocity of the wave that propagates through the specimen is higher. It can be seen in Fig. 7a that, despite having close compressive strength values, the S90A10-40 and S100-40AE1.0 mixtures presented values of ultrasound pulse velocity with a significant difference $(160 \mathrm{~m} / \mathrm{s})$ between them. A reasonable explanation for this phenomenon is attributed to the filler effect and resistance of SBA. Even with impaired compaction, the high fineness of

Table III - Compressive strength (MPa) results (mean \pm standard deviation) of mortars after 3 and 7 days of curing.

\begin{tabular}{cccc}
\hline Sample & w/b ratio & 3 days & 7 days \\
\hline S100-28 & & $70.5 \pm 0.8$ & $86.2 \pm 2.9$ \\
S100-28AE1.0 & 0.28 & $50.1 \pm 2.0$ & $61.4 \pm 1.3$ \\
S90A10-28 & & $50.1 \pm 3.3$ & $62.4 \pm 5.5$ \\
S90A10-28AE1.0 & & $59.8 \pm 0.5$ & $74.9 \pm 3.7$ \\
\hline S100-40 & & $54.5 \pm 1.1$ & $69.3 \pm 1.1$ \\
S100-40AE1.0 & \multirow{2}{*}{0.40} & $36.7 \pm 0.6$ & $46.9 \pm 0.2$ \\
S90A10-40 & & $44.5 \pm 0.8$ & $56.4 \pm 2.8$ \\
S90A10-40AE1.0 & & $41.3 \pm 1.0$ & $53.0 \pm 1.4$ \\
\hline
\end{tabular}

SBA helped in closing the pores. However, it was not enough to increase or maintain the compressive strength, as the SBA particles were rich in organic matter and consequently had low resistance to compression [22]. Particularly, the ultrasound test allowed a better understanding of the effect of $\mathrm{AE}$ in the S90A10-28AE1.0 mixture. As seen in Fig. 7a, this mixture presented a lower value than the analog mixture without the $\mathrm{AE}$ agent. As the ultrasound test is directly related to the porosity, it can be concluded that the AE admixture did not produce air bubbles, likely due to the unsuitable consistency of the mixture. On the other hand, it is remarkable that in the mixture with $w / b=0.40$, the $\mathrm{AE}$ worked more effectively, producing air bubbles and decreasing the porosity and the values of ultrasound pulse velocity.
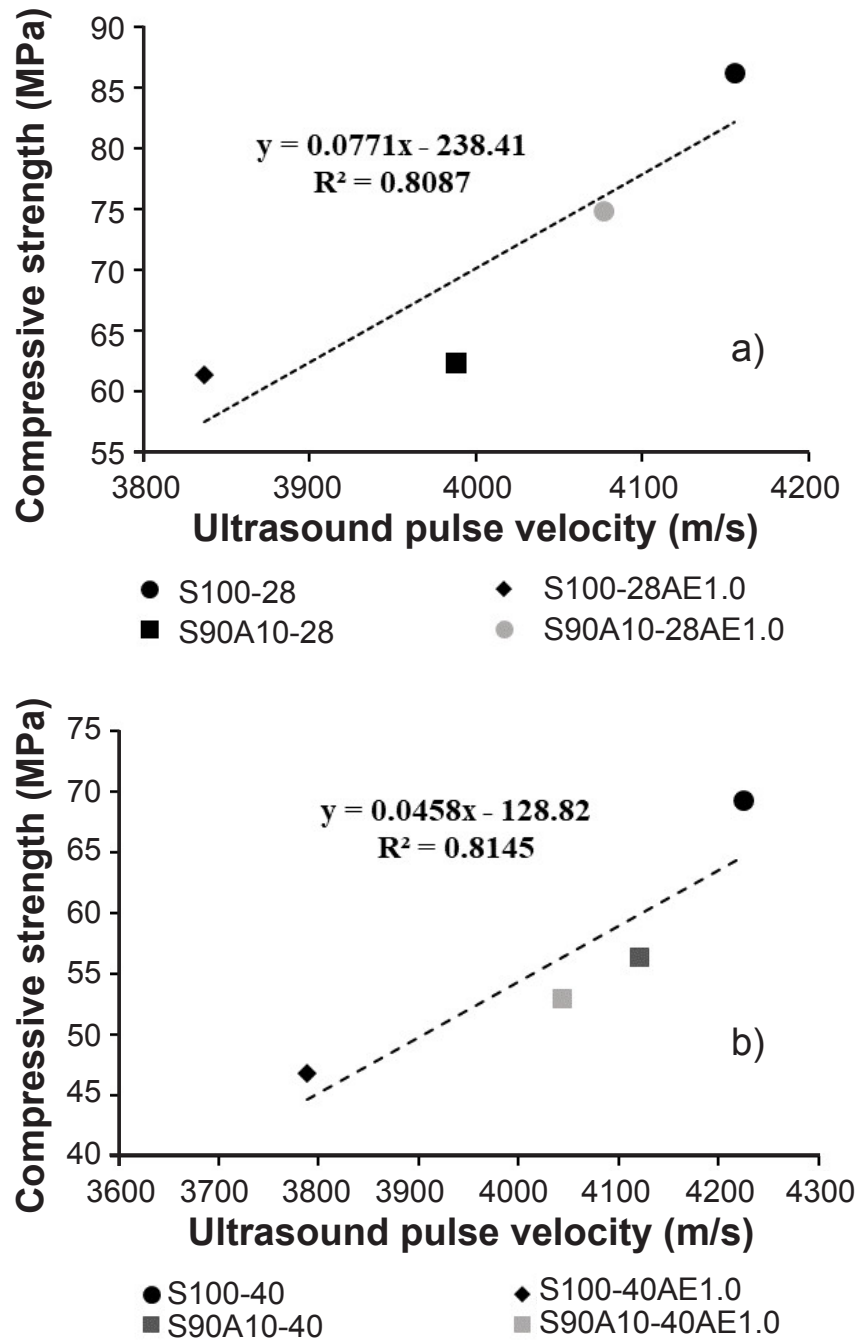

Figure 7: Results of ultrasonic pulse velocity vs. compressive strength at 7 days in mortars with water/binder ratio of: a) 0.28 ; and b) 0.40 .

\section{CONCLUSIONS}

From the results presented, it can be concluded that: i) mixtures with a content higher than $10 \%$ of ground sugarcane bagasse ash (G-SBA) proved to be unfeasible at 
water/binder (w/b) ratios of 0.28 and 0.40 due to the dry consistency of the mixtures, caused by the intense water absorption capacity of SBA; ii) the use of a polycarboxylatebased superplasticizer did not cause significant effect in the alkali-activated mixtures; on the other hand, the airentraining (AE) agent had a slight effect on enhancing the flowability of the mixtures; this showed that the airentraining agent had a greater chemical stability than the polycarboxylate superplasticizer; iii) no change in the mineralogical composition of the hydrated products of the pastes with the incorporation of SBA and AE was observed; iv) unexpectedly, the air-entraining admixture led to an increase in the compressive strength of the mixture with $10 \% \mathrm{G}-\mathrm{SBA}$ and $\mathrm{w} / \mathrm{b}=0.28$; this occurred probably due to presence of water in the admixture, which could enhance the compaction and allowed the expelling of voids; v) the air-entraining agent reduced the compressive strength in mixtures which presented sufficient consistency to allow this admixture to work and produce air bubbles; vi) G-SBA caused a $20 \%$ to $28 \%$ decrease in the compressive strength of mixtures; the use of AE agent can be combined with ash, as it only causes a drop in the resistance when the mixture is highly fluid; vii) the low potential of SBA as a filler was associated with a high content of organic matter because even helping to close the pores, the organic particles have low resistance. In the end, it was possible to suggest the incorporation of SBA with a high content of organic matter in contents below $10 \%$, considering the probable decrease in compressive strength. The employment of an air-entraining admixture can allow a better flowability if the mixture presents a dry consistency.

\section{ACKNOWLEDGEMENTS}

The authors thank PROPESQ (UFPE) and CAPES for the financial support, and the companies Mizu Cimentos, Usina Petribu S/A, and Pernambuco Química S/A for providing the materials for this research.

\section{REFERENCES}

[1] R.M. Andrew, Earth Syst. Sci. Data 10 (2018) 195.

[2] B. Lothenbach, K. Scrivener, R.D. Hooton, Cem. Concr. Res. 41 (2011) 1244.

[3] M.A. Cincotto, Concr. Constr. 47, 95 (2019) 46.

[4] J.L. Provis, Cem. Concr. Res. 114 (2018) 40.

[5] F. Pacheco-Torgal, J.A. Labrincha, C. Leonelli, A. Palomo, P. Chindaprasirt (Eds.), "Handbook of alkaliactivated cements, mortars and concretes", Elsevier (2015).

[6] V.M. John, "Cimentos de escória ativada com silicatos de sódio", Dr. Thesis, USP, S. Paulo (1995).

[7] J.G. Jang, N.K. Lee, H.K. Lee, Constr. Build. Mater. 50 (2014) 169.

[8] V. Bílek, L. Kalina, R. Novotny, Constr. Build. Mater. 166 (2018) 564.

[9] M. Hojati, A. Radlin, Constr. Build. Mater. 150 (2017) 808.
[10] Z. Li, M. Nedeljković, B. Chen, G. Ye, Cem. Concr. Res. 122 (2019) 30.

[11] G. Fang, W.K. Ho, W. Tu, M. Zhang, Constr. Build. Mater. 172 (2018) 476.

[12] N. Marjanovi, M. Komljenovi, Z. Ba, V. Nikoli, R. Petrovi, Ceram. Int. 41 (2015) 1421.

[13] R.J. Thomas, S. Peethamparan, Constr. Build. Mater. 93 (2015) 49.

[14] A. Mobili, A. Belli, C. Giosuè, T. Bellezze, F. Tittarelli, Cem. Concr. Res. 88 (2016) 198.

[15] J.L. Provis, A. Palomo, C. Shi, Cem. Concr. Res. 78 (2015) 110.

[16] F. Puertas, S. Martínez-Ramírez, S. Alonso, T. Vázquez, Cem. Concr. Res. 30 (2000) 1625.

[17] L.U.D. Tambara Júnior, M. Cheriaf, J.C. Rocha, Materials 11 (2018) 1.

[18] A.G.N.D. Darsanasiri, F. Matalkah, S. Ramli, K. AlJalode, A. Balachandra, P. Soroushian, J. Build. Eng. 19 (2018) 36.

[19] A. Herrmann, A. Koenig, F. Dehn, Struct. Concr. 19 (2018) 918.

[20] F. Martirena, J. Monzó, Cem. Concr. Res. 114 (2018) 57.

[21] G.C. Cordeiro, R.D.T. Filho, R.S. De Almeida, Adv. Appl. Ceram. 110 (2011) 453.

[22] G.C. Cordeiro, L.M. Tavares, R.D. Toledo Filho, Cem. Concr. Res. 89 (2016) 269.

[23] S.M. Torres, V.E. De Lima, P.D.A. Basto, N.T.D.A. Júnior, A.A.D.M. Neto, Constr. Build. Mater. 264 (2020) 120684.

[24] N. Chusilp, C. Jaturapitakkul, K. Kiattikomol, Constr. Build. Mater. 23 (2009) 3523.

[25] E.V. Morales, E. Villar-Cociña, M. Frías, S.F. Santos, H. Savastano, Cem. Concr. Compos. 31 (2009) 22.

[26] S.E. Fernandes, M.M. Tashima, J.C.B. de Moraes, D.B. Istuque, C.F. Fioriti, J.L.P. Melges, J.L. Akasaki, Rev. Mater. 20 (2015) 909.

[27] M.W. Clark, L.M. Despland, N.J. Lake, L.H. Yee, M. Anstoetz, E. Arif, J.F. Parr, P. Doumit, Heliyon 3 (2017) e00294.

[28] A. Bahurudeen, D. Kanraj, V. Gokul Dev,M. Santhanam, Cem. Concr. Compos. 59 (2015) 77.

[29] E.M.R. Fairbairn, B.B. Americano, G.C. Cordeiro, T.P. Paula, R.D. Toledo, M.M. Silvoso, J. Environ. Manage. 91 (2010) 1864.

[30] A.L. Yadav, V. Sairam, L. Muruganandam, K. Srinivasan, J. Clean. Prod. 245 (2019) 118854.

[31] G.C. Cordeiro, R.D.T. Filho, E.M.R. Fairbairn, IBRACON Struct. Mater. 3 (2010) 50.

[32] K.C.P. Faria, R.F. Gurgel, J.N.F. Holanda, J. Environ. Manage. 101 (2012) 7.

[33] A. Bahurudeen, M. Santhanam, Cem. Concr. Compos. 56 (2015) 32.

[34] J. Payá, J. Monzó, M.V. Borrachero, M.M. Tashima, L. Soriano, in "Waste and supplementary cementitious materials in concrete", R. Siddique, P. Cachim (Eds.), Woodhead Publ., UK (2018) 559. 
[35] V. Ríos-Parada, V.G. Jiménez-Quero, P.L. ValdezTamez, P. Montes-García, Constr. Build. Mater. 157 (2017) 83.

[36] A. Sales, S.A. Lima, Waste Manage. 30 (2010) 1114.

[37] R.M. Bega, "Aplicação de cinza do bagaço de canade-açúcar em latossolo cultivado com cana-de-açúcar”, Dr. Thesis, Un. Est. S. Paulo, Jaboticabal (2014).

[38] A. Pereira, J.L. Akasaki, J.L.P. Melges, M.M. Tashima, L. Soriano, M.V. Borrachero, J. Monzó, J. Payá, Ceram. Int. 41 (2015) 13012.

[39] V.N. Castaldelli, J.C.B. Moraes, J.L. Akasaki, J.L.P. Melges, J. Monzó, M.V. Borrachero, L. Soriano, J. Payá, M.M. Tashima, Fuel 174 (2016) 307.

[40] V.N. Castaldelli, J.L. Akasaki, J.L.P. Melges, M.M. Tashima, L. Soriano, M.V. Borrachero, J. Monzó, J. Payá, Materials 6 (2013) 3108.

[41] ABNT NBR 16605, "Portland cement and other powdery materials: determination of specific gravity", Braz. Ass. Techn. Stand., Rio Janeiro (2017).

[42] ABNT NBR 16372, "Portland cement and other powdery materials: determination of Blaine fineness", Braz. Ass. Techn. Stand., Rio Janeiro (2015).

[43] N. Roussel, C. Stefani, R. Leroy, Cem. Concr. Res. 35 (2005) 817.

[44] M. Palacios, F. Puertas, Cem. Concr. Res. 35 (2005) 1358.

[45] X. Lin, B. Liao, J. Zhang, S. Li, J. Huang, H. Pang, Constr. Build. Mater. 210 (2019) 162.

[46] P.C. Aïtcin, Concreto de alto desempenho, PINI, S. Paulo (2000).

[47] A.A. Melo Neto, M.A. Cincotto, W. Repette, Cem. Concr. Res. 38 (2008) 565.

[48] A.A. Melo Neto, "Estudo da retração em argamassa com cimento de escória ativada", M.Sc. Diss., Un. S. Paulo,
S. Paulo (2002).

[49] N.T. Araújo Júnior, "Concreto de alta resistência produzido com escória álcali-ativada", M.Sc. Diss., Un. Fed. Pernambuco, Recife (2019).

[50] T. Bakharev, J.G. Sanjayan, Y.B. Cheng, Cem. Concr. Res. 30 (2000) 1367.

[51] M. Palacios, P.F.G. Banfill, F. Puertas, ACI Mater. J. 105 (2008) 140.

[52] M. Palacios, Y.F. Houst, P. Bowen, F. Puertas, Cem. Concr. Res. 39 (2009) 670.

[53] ABNT NBR 7215, "Cimento Portland: determinação da resistência de corpos de prova cilíndricos", Braz. Ass. Techn. Stand., Rio Janeiro (2019).

[54] O.R. Ogirigbo, L. Black, Constr. Build. Mater. 126 (2016) 496.

[55] N. You, B. Li, R. Cao, J. Shi, C. Chen, Y. Zhang, Constr. Build. Mater. 227 (2019) 116614.

[56] W. Kurdowski, Cement and concrete chemistry, Springer (2014).

[57] A.M. Humad, K. Habermehl-Cwirzen, A. Cwirzen, Materials 12 (2019) 1.

[58] H. El-Hassan, Y. Shao, Z. Ghouleh, J. Mater. Civ. Eng. 25 (2013) 799.

[59] T.M. Bolonini, A.M. Godoy, Geociências 36 (2017) 463.

[60] B. Walkley, R. San Nicolas, M.A. Sani, G.J. Rees, J.V. Hanna, J.S.J. van Deventer, J.L. Provis, Cem. Concr. Res. 89 (2016) 120.

[61] B. Walkley, A. Kashani, M.A. Sani, T.D. Ngo, P. Mendis, J. Mater. Sci. 53 (2018) 9486.

[62] V. Estolano, S. Fucale, J.O. Vieira Filho, D. Gabriel, Y. Alencar, Rev. Mater. 23 (2018) e-11974.

(Rec. 13/02/2020, Rev. 01/07/2020, 22/09/2020, Ac. $08 / 10 / 2020)$ 